\title{
Cross-border movement of older patients: a descriptive study on health service use of Japanese retirees in Thailand
}

\author{
Yumiko Miyashita ${ }^{1 *}$, Chutima Akaleephan ${ }^{1}$, Nima Asgari-Jirhandeh ${ }^{2}$ and Channarong Sungyuth ${ }^{3}$
}

\begin{abstract}
Background: Thailand's policy to promote long-stay tourism encourages Japanese retirees to relocate to Thailand. One concern of such an influx is the impact of these elderly foreign residents on the Thai health system. This study aims to reveal the current use of and needs for health services amongst Japanese retirees residing in various locations in Thailand.
\end{abstract}

Methods: In collaboration with nine Japanese self-help clubs in Bangkok, Chiang Mai, Chiang Rai, and Phuket, questionnaire surveys of Japanese long-stay retirees were conducted from January to March 2015. The inclusion criteria were being $\geq 50$ years of age and staying in Thailand for $\geq 30$ days in the previous 12 months while the main exclusion criteria included relocation by company, relocation due to marriage, or working migrants.

Results: The mean age of the 237 eligible participants was 68.8 , with $79.3 \%$ of them being male, $57.8 \%$ having stayed in Thailand for $\geq 5$ years, $63.3 \%$ having stayed in Thailand for $\geq 300$ days in the previous 12 months and $33 \%$ suffering from chronic diseases or sequelae. Of the 143 who had health check-ups in the previous 12 months, $48.3 \%$ did so in Thailand. The top 3 diseases treated either in Thailand or Japan in the previous 12 months were dental diseases (50 patients), hypertension (44 patients), and musculoskeletal disorders (41 patients), with the rate of treatment in Thailand standing at 46.0, 47.7, and 65.9\%, respectively. Of the 106 who saw a doctor in Thailand in the same period, 70.8\% did so less than once a month. Only $23.2 \%$ of the participants preferred to receive medical treatment for serious conditions in Thailand. However, this number rose to 32.9\% for long-term care (LTC) use.

Conclusion: The usage of Thai health services amongst Japanese long-stay retirees is currently limited as they prefer going back to Japan for health screenings and treatment of chronic or serious diseases. However, the number of Japanese residents requiring health services including LTC and end-of-life care is expected to increase. The potential impact of promoting long-stay tourism on the Thai public health should be acknowledged and investigated by the Thai government, including the tourism authority.

Keywords: Trade in health services, Long-stay tourism, Retirees, Health service use, Japanese, Thailand

\section{Background}

As in many other countries, Thailand's health sector, which has been closed and nationally focused, is gradually feeling the impact of globalization with the increasing awareness that health care goods and services provided for foreign patients or firms abroad can be a potential income-generating mechanism for the economy [1]. Substantial growth is seen

\footnotetext{
* Correspondence: yumiko@ihpp.thaigov.net

'International Health Policy Program, Thailand, Ministry of Public Health,

Tiwanon Road, Nonthaburi 11000, Thailand

Full list of author information is available at the end of the article
}

in trade in health services via "consumption abroad", which refers to the cross-border movement of patients [2]. Currently, many developing countries attract patients from developed countries as well as neighboring countries by providing high quality and affordable treatment, specialized services, or alternative therapies [3]. This benefits the destination countries via the inward flow of funds into the economy, allowing them to upgrade health care infrastructure and technologies and increase employment of health personnel. Conversely, unless properly managed, this model has the potential to widen the gap between private health 
care providers focusing on foreign patients and wealthy nationals - who can afford technologically-advanced and high-quality health care - and the rest of the health care providers available to the general public [2-6].

Thailand is the largest exporter of health services via consumption abroad in Southeast Asia [6] with 1.4 million foreign patients in 2013 [7], owing to the efforts of private hospitals to develop a new customer base in cooperation with the government's medical hub policy. The medical hub policy is the government's overall strategy for ensuring that Thailand becomes medical hub of Asia. It has four components (see Fig. 1) of which Medical Service Hub is one. The Medical Service Hub focuses on three groups of potential foreign patients: i) expatriates living in Thailand; ii) general tourists who will need medical attention while in Thailand; and iii) medical tourists who come specifically for medical reasons.

The largest group of foreign patients are Japanese [6, 7], most of whom are expatriates [8]. Currently there are few medical tourists from Japan since the Japanese universal health insurance scheme allows Japanese to get quality health care in Japan at a moderate price. Thus, this paper focuses on Japanese expatriates only. In 2014, 1.3 million Japanese visited Thailand [9]. The registration data of overseas residents in Thailand indicated that the number of Japanese expatriates had doubled to 64,000 compared to a decade ago [10], thereby making Thailand the country with the fifth-highest Japanese expatiate population [11]. The vast majority of these people were corporate employees and their families who had been transferred from Japan [11]. Notably, there were more than 10,000 older persons aged 60 and above [11], reflecting population aging at home and the promotion of long-stay tourism in both countries.

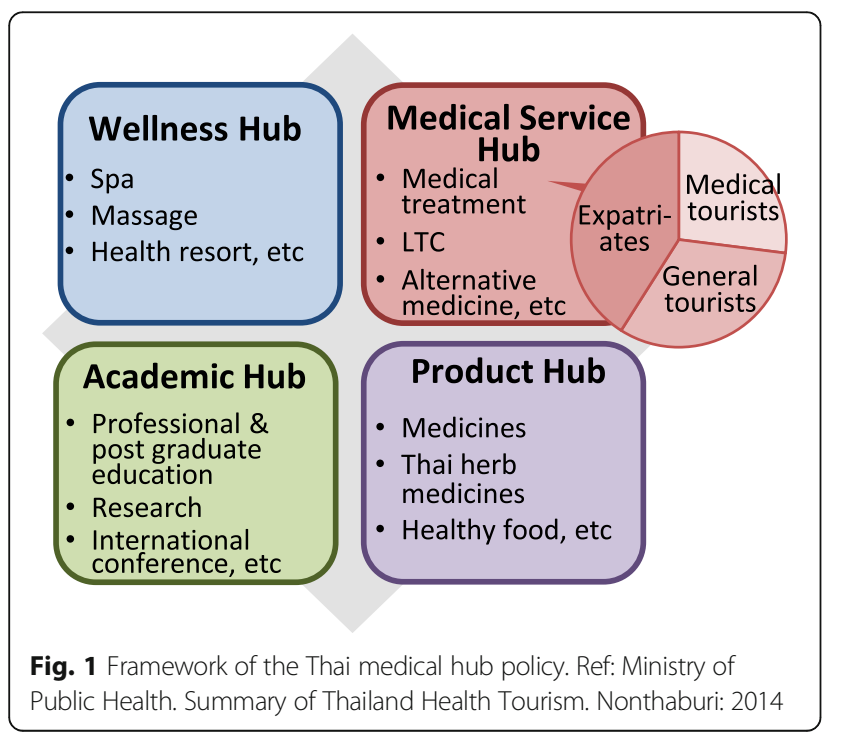

International long-stay tourism - also known as international retirement migration - became popular in Western countries in the 1960s and has gradually spread globally [12]. The Thai government, particularly the Tourism Authority of Thailand (TAT), has been actively promoting long-stay tourism since 2001 as part of the national development strategy [13]. "Long Stay" is regarded as staying in the country for more than 30 days and not for sightseeing activities or working but with a purpose of living with the intention to return to the home countries [14]. As retirees are the main target group, a special renewable one-year visa is provided for people aged 50 years and above who fulfill certain financial criteria. The Thai government has designated Japan as a primary target country $[13,15]$.

In Japan, outbound long-stay tourism for leisure was introduced in the 1990s and has been successfully promoted by the private sector [16]. The favored destinations have recently shifted from English-speaking developed countries such as US (particularly Hawaii), Canada, and Australia to Southeast Asian countries due to the low cost of living, short flight time, warm weather, and availability of a longterm visa [17]. Thailand is Japan's second-most popular long-stay destination [18]. While the exact number of long-stay retirees in Thailand is unknown due to the variety in types of stays and visas [19, 20], Immigration Bureau statistics suggest that at least 3,000 Japanese stayed in Thailand for over a year using retirement visas in 2014 [21], up from 1,400 in 2007 [22].

Long-stay retirees are closely linked to health services. First, according to a survey by the TAT, one of the main determinants of long-term stay in Thailand for Japanese nationals is the availability of medical services [15]. Secondly, older people require more frequent treatment compared to younger age groups due to a higher prevalence of chronic diseases. Previous surveys conducted in the 2000s revealed that among Japanese adults visiting or living in Thailand, the most common causes for seeking treatment were acute respiratory diseases, acute digestive tract disorders, and infections; chronic diseases such as metabolic disorders or circulatory diseases had lower proportions $[8,23]$. However, the volume and pattern of medical service use may be shifting due to the increase in the number of Japanese retirees in recent years. Thirdly, in addition to the pull factor from Thailand, the increasing shortage of care workers and facilities for long-term care (LTC) for the elderly with difficulties in activities of daily living (ADL) in Japan is also convincing Japanese retirees to move abroad [13, 16, 24]. Hence, the growing number of long-stay retirees will increase medical and long-term care demand in Thailand, and thus have an impact on the overall Thai health care system - which already faces a shortage of human resources and has to tackle its own aging population. 
Information on actual health care use of long-stay retirees in foreign countries is difficult to come by. Even in Western countries with a history of retirement migration, there are only a small number of studies on health care issues of long-stay retirees, most of which are qualitative studies on their health care experience abroad [25-27]. Previous studies of Japanese retirees in Thailand were mostly conducted in Chiang Mai, a mecca for long-stay Japanese located in the north of Thailand, and focused on their motivations for coming or leaving Thailand [24, 28, 29 ], how they adjusted to the host country [20], or improvement of information provision [14]. Few studies reported health care service use quantitatively except for a study in 2007 in Chiang Mai which focused on the attitude of Japanese long-stay retirees towards Thai medical services [30]. Apart from the limited data gained from this study in Chiang Mai, very little information is available on health care demand, the frequency of medical service use, or disease patterns of Japanese retirees in Thailand.

Therefore, this study aims to reveal the current use of and needs for health services amongst Japanese longstay retirees, with a view of providing insight into the impact of long-stay tourism on the Thai health system.

\section{Methods}

A cross-sectional survey was conducted from January to March 2015, coinciding with the high season for Japanese long-stay tourists in Thailand. Convenience sampling methods were used in which study participants were recruited in cooperation with nine Japanese self-help clubs on a voluntary basis from different cities: Bangkok (3), Chiang Mai (3), Chiang Rai (1), and Phuket (2). The questionnaire was self-administered and anonymized. Sampling and data collection methods differed depending on the club's style of activities and member registration. In five clubs, questionnaires were distributed during periodical meetings and collected at the meetings or posted back. Postal surveys were conducted in the remaining four clubs. In two of the clubs, questionnaires were posted to the members aged 50 and over and collected by post. In another club, questionnaires were handed out at the office and returned by mail. In the final club, some members were handed out questionnaires in the office and returned it by mail while others were interviewed by phone.

The focus of the study was Japanese long-stay retirees, including those who are semi-retired. Inclusion criteria were i) at least 50 years old according to the requirement of the long-stay/retirement visa and ii) staying in Thailand for more than 30 days in the previous 12 months. Exclusion criteria include i) expatriate personnel and their spouses who were relocated to Thailand by Japanese companies; ii) relocation due to marriage; iii) working migrants; iv) new arrivals who started their long-term stay in the past three months; or v) individuals who left more than $30 \%$ of the questionnaire blank. Relocation due to marriage was identified by two variables: those who started their long-term stay before reaching 50 years of age and had a Thai spouse. Working migrants were assumed to be those who started their long-term stay in Thailand before reaching 50 years of age and received their primary income from working in Thailand.

The data obtained included i) basic demographics and socio-economic background such as age, sex, marital status, and education level; ii) condition of stay including the number of years living in Thailand as a long-stay visitor, number of days staying in Thailand in the previous 12 months, and living expense per month; iii) health status such as BMI calculated by height and weight, self-reported chronic diseases or sequelae as well as health related QOL obtained by the EuroQol-5D-5 L [31]; iv) use of health services in the previous 12 months, including health check-ups, cancer screenings, LTC services, and doctor's visits; v) use of medical services in the previous 12 months such as the frequency of visiting doctors, experience and duration of hospital stays, type of diseases, and medical expenses and its sources; and vi) future intention of using health services, i.e. a preferable place for LTC or medical treatment for severe diseases. LTC services herein refer to physical assistance with bathing, toileting, meals, etc. as well as sputum suction or tube feeding. Descriptive statistics were used with dividing the participants into three groups by location: Bangkok, Chiang Mai, and other areas (hereinafter "Other area").

The study was approved by the ethical committee of the Institute for the Development of Human Research Protections, Thailand. Implied consent was substituted for written consent to assure anonymity of participants by considering their filled and returned questionnaire as consent for participation in the survey; this implied consent principle was explained beforehand. A letter of approval was also obtained from the representative of each Japanese club.

\section{Results \\ Study participants}

The questionnaires were distributed to 341 persons, and 262 responded $(76.8 \%)$. Twenty-five persons were excluded in the following order: less than 50 years old (5); less than 30 days of stay (3); relocation due to marriage (9); working migrants (3); new arrivals within three months (2); and greater than $30 \%$ of the questionnaire left unfilled (3). None of the participants were expatriate staff relocated from Japan or their spouses. As a result, data from 237 persons (69.5\%) were analyzed as shown in Fig. 2.

\section{Basic demographics and condition of long stay}

Among the eligible study participants living in Bangkok (56), Chiang Mai (144), and Other area (37), 188 were males (79.3\%). The mean age was 68.8 years old (SD 5.6) 


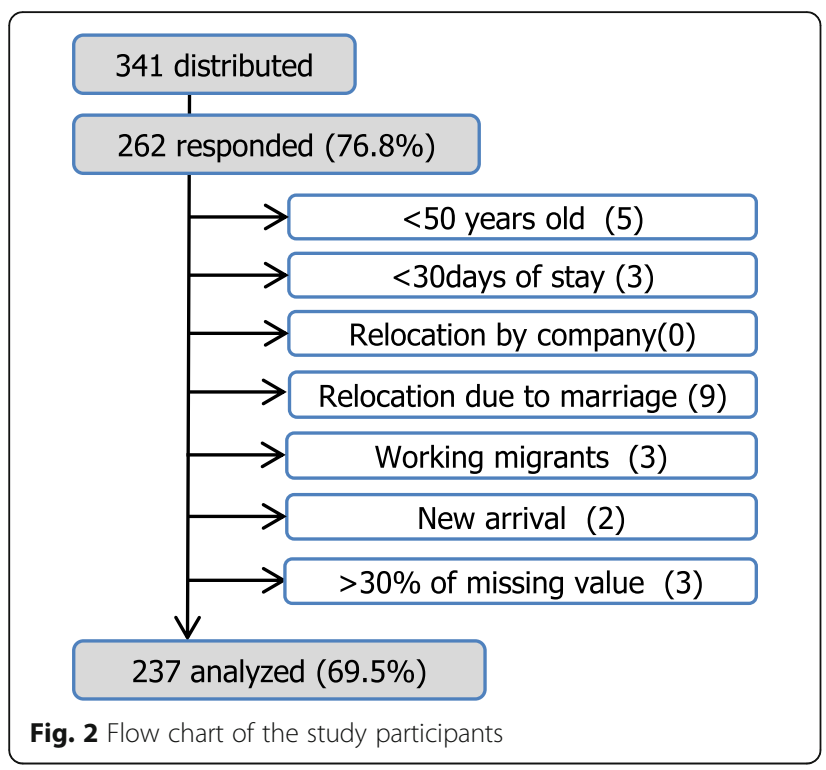

and those aged 75 and more accounted for 16.0\%. Retirement visas topped the list for visa status, with 197 persons $(83.1 \%)$ using them.

A difference was observed in the participants' socioeconomical background and condition of stay based on the area of residence. People married to Japanese or other non-Thais made up the largest group in Bangkok and Chiang Mai (55.4 and 49.3\%, respectively), while those married to Thais accounted for $45.9 \%$ in Other area. As for living status in Thailand, living alone was most common in Bangkok (46.4\%), including 10 persons who were married but not living together in Thailand. In Chiang Mai and Other area, couple households accounted for 47.2 and $48.6 \%$, respectively. Households with a child accounted for a small proportion in Bangkok (7.1\%) and Chiang Mai (14.6\%) but was commonly observed in Other area (29.7\%). Living with a parent was a rare case in all areas, with only four observations in total $(1.7 \%)$. The percentage of those who had stayed in Thailand for more than a year before the current long-stay status - considered mostly as an expatriate personnel or their family - was higher in Bangkok (33.9\%) compared to Chiang Mai (13.9\%) and Other area (18.9\%). The average monthly household income and expenditure were highest in Bangkok at JPY 300,867 (USD 2,844 ${ }^{1}$ ) and THB 61,660 (USD 1,898 ${ }^{2}$ ), followed by Chiang Mai with JPY 265,300 (USD 2,508) and THB 50,282 (USD 1,548), and lowest in Other area with JPY 194,400 (USD 1,838) and THB 42,667 (USD 1,314), respectively.

The mean number of years for Long Stay was 6.4 years (SD 4.7). Fifty-nine persons (24.9\%) had been staying for more than 10 years as a long-stay visitor, and the rate rose to $35.1 \%$ among the respondents in Other area. The median days (1st quartile(Q1)-3rd quartile(Q3)) of stay in Thailand in the previous 12 months was 300 (200-335) days in Bangkok, 320 (270-350) days in Chiang Mai, and 330 (300-360) days in Other area. During the previous 12 months, the most common number of trips to Japan was twice and above (44.7\%), and this was particularly higher among Bangkok residents (66.1\%). On the other hand, $20.3 \%$ did not go back to Japan in the previous 12 months and the Other area rated higher than other cities (29.7\%). The percentage of those who kept residence in Japan was $80.4 \%$ in Bangkok, $75.0 \%$ in Chiang Mai, and $51.4 \%$ in Other area. Those who kept residential registration in Japan - a requirement for one to be covered by the Japanese national health insurance (Kokuho) - was $57.1 \%$ in Bangkok, 44.4\% in Chiang Mai, and 29.7\% in Other area (Table 1).

\section{Health status and health service use in the previous 12 months}

Most of the participants were found to be relatively healthy. Table 2 shows that the majority $(63.7 \%)$ were within the normal BMI range (18.5-24.9), and eight persons (3.4\%) were underweight (BMI less than 18.5). The rate of overweight (BMI equal to or greater than 25) was lower in Other area (13.5\%) compared to Chiang Mai (38.2\%) and Bangkok (30.4\%). There were 79 persons (33.3\%) who had chronic diseases or sequelae from diseases or injuries. As for health-related QOL, the mean EQ-5D Index Score was 0.91 out of 1.0 .

Rehabilitation and LTC service use in Thailand in the previous 12 months was small. Eleven persons (4.6\%) received rehabilitation and five used LTC services. Only one $(0.4 \%)$ used LTC services for himself at an elderly nursing unit in hospital, while the remaining four participants (1.7\%) used LTC services for a disabled family member, three of whom used at-home services. None of the participants used residential care services.

Interesting health seeking behaviors of Japanese retirees were observed. Of the 143 respondents (60.3\%) who received health check-ups in the previous 12 months, most received it in Japan rather than in Thailand. The responses showed that 50 persons $(35.0 \%)$ received check-ups in Thailand, 74 (51.7\%) in Japan, and 19 (13.3\%) in both countries. The number and rate of retirees who received screenings for stomach, lung, and colon cancers were 89 (37.6\%), 87 (36.7\%), and 100 $(42.2 \%)$, respectively. On average, the vast majority of them received cancer screenings in Japan, comprising $69.9 \%$ in Japan, $23.2 \%$ in Thailand, and $6.9 \%$ in both countries. However, of the 147 (62.0\%) who saw a doctor for treatment in the previous 12 months, many people did so in Thailand, comprising 66 persons (44.9\%) in 
Table 1 Basic characteristics and condition of Long Stay

\begin{tabular}{|c|c|c|c|c|c|c|c|c|}
\hline & $\begin{array}{c}\text { Bangkok } \\
\text { n }\end{array}$ & $\begin{array}{c}(n=56) \\
\%\end{array}$ & $\begin{array}{c}\text { Chiang Mai } \\
\mathrm{n}\end{array}$ & $\begin{array}{c}(n=144) \\
\%\end{array}$ & $\begin{array}{c}\text { Other } \\
n\end{array}$ & $\begin{array}{c}(n=37) \\
\%\end{array}$ & $\begin{array}{c}\text { Total } \\
\mathrm{n}\end{array}$ & $\begin{array}{c}(n=237) \\
\%\end{array}$ \\
\hline \multicolumn{9}{|l|}{ Sex } \\
\hline Male & 45 & 80.4 & 110 & 76.4 & 33 & 89.2 & 188 & 79.3 \\
\hline Female & 11 & 19.6 & 34 & 23.6 & 4 & 10.8 & 49 & 20.7 \\
\hline \multicolumn{9}{|l|}{ Age } \\
\hline Mean (SD) & 69.1 & (5.6) & 68.3 & $(5.7)$ & 70.3 & $(4.8)$ & 68.8 & (5.6) \\
\hline \multicolumn{9}{|l|}{ Visa type: } \\
\hline Retirement & 47 & 83.9 & 121 & 84.0 & 29 & 78.4 & 197 & 83.1 \\
\hline Other & 7 & 12.5 & 20 & 13.9 & 6 & 16.2 & 33 & 13.9 \\
\hline \multicolumn{9}{|l|}{ Marital status } \\
\hline Single, divorced or bereaved & 20 & 35.7 & 32 & 22.2 & 5 & 13.5 & 57 & 24.1 \\
\hline Married to non-Thai & 31 & 55.4 & 71 & 49.3 & 15 & 40.5 & 117 & 49.4 \\
\hline Married to Thai & 5 & 8.9 & 39 & 27.1 & 17 & 45.9 & 61 & 25.7 \\
\hline \multicolumn{9}{|l|}{ Living status } \\
\hline Alone & 26 & 46.4 & 41 & 28.5 & 7 & 18.9 & 74 & 31.2 \\
\hline With partner only & 21 & 37.5 & 68 & 47.2 & 18 & 48.6 & 107 & 45.1 \\
\hline Other & 7 & 12.5 & 30 & 20.8 & 12 & 32.4 & 49 & 20.7 \\
\hline \multicolumn{9}{|c|}{ Lived in Thailand for $>1$ year before Long Stay status } \\
\hline Yes & 19 & 33.9 & 20 & 13.9 & 7 & 18.9 & 46 & 19.4 \\
\hline No & 35 & 62.5 & 122 & 84.7 & 30 & 81.1 & 187 & 78.9 \\
\hline \multicolumn{9}{|l|}{ Monthly household income (USD) } \\
\hline Mean (SD) & 2844 & $(1306)$ & 2508 & $(1384)$ & 1838 & (873) & 2478 & $(1329)$ \\
\hline \multicolumn{9}{|c|}{ Monthly household living expenditure (USD) } \\
\hline Mean (SD) & 1898 & (779) & 1548 & (643) & 1314 & (612) & 1590 & (695) \\
\hline \multicolumn{9}{|l|}{ Years of Long-stay in Thailand } \\
\hline Mean (SD) & 6.4 & $(5.2)$ & 5.9 & $(4.2)$ & 8.3 & $(5.4)$ & 6.4 & (4.7) \\
\hline \multicolumn{9}{|c|}{ Days of stay in Thailand in the previous 12 months } \\
\hline Median (Q1-Q3) & 300 & $(200-335)$ & 320 & $(270-350)$ & 330 & $(300-360)$ & 300 & $(270-350)$ \\
\hline \multicolumn{9}{|c|}{ Number of trips to Japan in the previous 12 months } \\
\hline 0 & 4 & 7.1 & 33 & 22.9 & 11 & 29.7 & 48 & 20.3 \\
\hline 1 & 13 & 23.2 & 49 & 34.0 & 14 & 37.8 & 76 & 32.1 \\
\hline$\geq 2$ & 37 & 66.1 & 59 & 41.0 & 10 & 27.0 & 106 & 44.7 \\
\hline \multicolumn{9}{|l|}{ Keeping a home in Japan } \\
\hline Yes & 45 & 80.4 & 108 & 75.0 & 19 & 51.4 & 172 & 72.6 \\
\hline No & 10 & 17.9 & 36 & 25.0 & 18 & 48.6 & 64 & 27.0 \\
\hline \multicolumn{9}{|l|}{ Residential registration in Japan } \\
\hline Registered & 32 & 57.1 & 64 & 44.4 & 11 & 29.7 & 107 & 45.1 \\
\hline Removed & 23 & 41.1 & 78 & 54.2 & 26 & 70.3 & 127 & 53.6 \\
\hline
\end{tabular}

Thailand, 41 (27.9\%) in Japan, and 40 (27.2\%) in both countries.

As shown in Fig. 3, a large number of people were treated either in Thailand or Japan in the previous 12 months for dental diseases (50 cases; $21.1 \%$ ), hypertension (44 cases; 18.6\%), musculoskeletal disorders (41 cases; 17.3\%), gastric disorders (27 cases; $11.4 \%$ ), eye diseases (23 cases; 9.7\%) and diabetes (22 cases; 9.3\%). Half of the patients received treatment only in Japan for dental diseases (50.0\%), hypertension (50.0\%), eye diseases (47.8\%), and diabetes (50.0\%). On the other hand, disease groups with a high rate of treatment in Thailand 
Table 2 Health status and health service use in the previous 12 months

\begin{tabular}{|c|c|c|c|c|c|c|c|c|}
\hline & Bangkok & $(n=56)$ & Chiang Mai & $(n=144)$ & Other & $(n=37)$ & Total & $(n=237)$ \\
\hline & $n$ & $\%$ & $n$ & $\%$ & $n$ & $\%$ & $n$ & $\%$ \\
\hline \multicolumn{9}{|l|}{ BMl } \\
\hline$<18.5$ & 3 & 5.4 & 4 & 2.8 & 1 & 2.7 & 8 & 3.4 \\
\hline $18.5-24.9$ & 36 & 64.3 & 84 & 58.3 & 31 & 83.8 & 151 & 63.7 \\
\hline$\geq 25$ & 17 & 30.4 & 55 & 38.2 & 5 & 13.5 & 77 & 32.5 \\
\hline \multicolumn{9}{|l|}{ Chronic disease or sequelae } \\
\hline Have & 19 & 33.9 & 43 & 29.9 & 17 & 45.9 & 79 & 33.3 \\
\hline Don't have & 36 & 64.3 & 78 & 54.2 & 19 & 51.4 & 133 & 56.1 \\
\hline \multicolumn{9}{|l|}{ QOL; EQ-5D-5 L index value } \\
\hline Mean (SD) & 0.93 & $(0.11)$ & 0.91 & $(0.13)$ & 0.89 & $(0.14)$ & 0.91 & $(0.13)$ \\
\hline \multicolumn{9}{|l|}{ Rehabilitation in Thailand } \\
\hline Received & 1 & 1.8 & 9 & 6.3 & 1 & 2.7 & 11 & 4.6 \\
\hline Not received & 55 & 98.2 & 131 & 91.0 & 34 & 91.9 & 220 & 92.8 \\
\hline \multicolumn{9}{|l|}{ LTC services in Thailand } \\
\hline \multicolumn{9}{|l|}{ Received } \\
\hline At Home & 0 & 0.0 & 2 & 1.4 & 1 & 2.7 & 3 & 1.3 \\
\hline Nursing home/residential care & 0 & 0.0 & 0 & 0.0 & 0 & 0.0 & 0 & 0.0 \\
\hline Elderly nursing unit in hospital & 0 & 0.0 & 0 & 0.0 & 1 & 2.7 & 1 & 0.4 \\
\hline Unspecified place & 0 & 0.0 & 1 & 0.7 & 0 & 0.0 & 1 & 0.4 \\
\hline Not received & 46 & 82.1 & 123 & 85.4 & 31 & 83.8 & 200 & 84.4 \\
\hline \multicolumn{9}{|l|}{ Health check-ups } \\
\hline Thailand & 10 & 17.9 & 36 & 25.0 & 4 & 10.8 & 50 & 21.1 \\
\hline Japan & 21 & 37.5 & 44 & 30.6 & 9 & 24.3 & 74 & 31.2 \\
\hline Both countries & 3 & 5.4 & 12 & 8.3 & 4 & 10.8 & 19 & 8.0 \\
\hline Not received & 20 & 35.7 & 48 & 33.3 & 18 & 48.6 & 86 & 36.3 \\
\hline \multicolumn{9}{|c|}{ Cancer screenings (Average: Stomach, Lung, and Colon) } \\
\hline Thailand & 6 & 10.7 & 13 & 9.0 & 2 & 6.3 & 21 & 9.0 \\
\hline Japan & 14 & 24.4 & 44 & 30.6 & 7 & 18.0 & 64 & 27.1 \\
\hline Both countries & 1 & 2.4 & 3 & 2.3 & 2 & 4.5 & 6 & 2.7 \\
\hline Not received & 34 & 60.1 & 79 & 54.9 & 25 & 66.7 & 137 & 57.9 \\
\hline \multicolumn{9}{|l|}{ Consulting a doctor } \\
\hline Thailand & 15 & 26.8 & 34 & 23.6 & 17 & 45.9 & 66 & 27.8 \\
\hline Japan & 10 & 17.9 & 26 & 18.1 & 5 & 13.5 & 41 & 17.3 \\
\hline Both countries & 10 & 17.9 & 25 & 17.4 & 5 & 13.5 & 40 & 16.9 \\
\hline Not received & 16 & 28.6 & 53 & 36.8 & 10 & 27.0 & 79 & 33.3 \\
\hline
\end{tabular}

were musculoskeletal disorders (65.9\%); skin diseases (75.0\%); prostatic hypertrophy (65.0\%); acute or allergic rhinitis and laryngitis (68.4\%); and injury (93.8\%). Only a few cases of cerebrovascular diseases (3) and ischemic heart diseases (3) were treated in Thailand. None of the participants were treated for mental diseases or malignant neoplasm in Thailand.

Among the 106 participants (44.7\%) who saw a doctor in Thailand in the previous 12 months (Table 3), 93 used private hospitals or clinics (87.7\%) while 25.4 and $22.7 \%$ of residents in Chiang Mai and Other area used public health facilities, respectively. Twenty-eight samples were observed to have visited medical facilities at least once a month (26.4\%). Twenty-three participants were admitted to a hospital $(21.7 \%)$ but 18 of them were discharged within a week (78.3\%) - including 12 within three days (52.2\%).

Table 4 shows that 31 respondents paid their entire medical costs out-of-pocket (29.2\%). Traveler's insurance was commonly used by retirees in Bangkok (56.0\%) and 


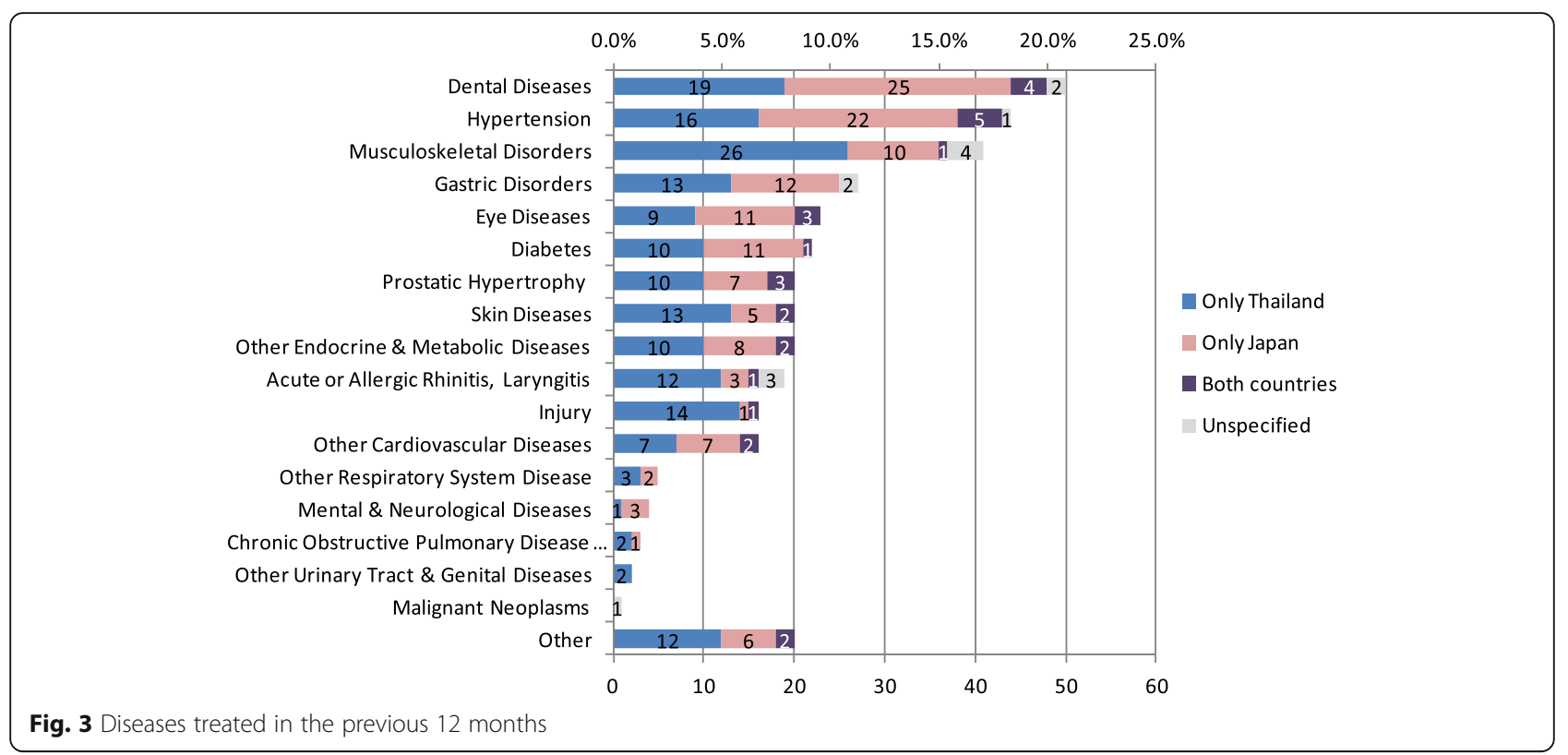

Chiang Mai (45.8\%), while none in Other area used it. The use of Japanese public health insurance accounted for $24.0 \%$ of the sample in Bangkok, 22.0\% in Chiang Mai, and $13.6 \%$ in Other area. The median (Q1-Q3) out-ofpocket medical costs in the previous 12 months was THB $5,000(0-27,500)$ or USD $154(0-847)$. Only 12 persons spent THB 50,000 (USD 1,539) or more $(11.3 \%$ ) and the maximum amount was THB 200,000 (USD 6,158).

\section{Future intention of use of health services}

The majority of participants intended to receive medical treatment in Japan in case of serious diseases (66.2\%). Those who preferred Thailand were 3 persons in Bangkok (5.4\%), 39 in Chiang Mai (27.1\%), and 13 in Other area (35.1\%). The number of participants who intended to receive LTC in Thailand in case they became severely disabled was 7 in Bangkok (12.5\%), 51 in Chiang Mai (35.4\%), and 20 in Other area (54.1\%). Among them, home care was the most preferred option (61.5\%) - especially true in Other area $(85.0 \%)$ - followed by care at nursing homes (17.9\%) (Table 5).

\section{Discussions}

The study suggests rapid aging among Japanese long-stay retirees with an increase from an average of 64.7 years old in a previous survey in Chiang Mai in 2007 [30] to 68.3 years old in Chiang Mai or 68.8 years old among the total participants. One reason may be that the original cohort continued to stay in Thailand while the other may be that new entrants are older due to an increase in the

Table 3 Use of medical services in Thailand in the previous 12 months

\begin{tabular}{|c|c|c|c|c|c|c|c|c|}
\hline & Bangkok & $(n=25)$ & Chiang Mai & $(n=59)$ & Other & $(n=22)$ & Total & $(n=106)$ \\
\hline & $n$ & $\%$ & $n$ & $\%$ & $n$ & $\%$ & $n$ & $\%$ \\
\hline \multicolumn{9}{|c|}{ Type of hospital/clinics (Multiple answer) } \\
\hline Private & 24 & 96.0 & 52 & 88.1 & 17 & 77.3 & 93 & 87.7 \\
\hline Public & 4 & 16.0 & 15 & 25.4 & 5 & 22.7 & 24 & 22.6 \\
\hline \multicolumn{9}{|l|}{ Frequency of doctor visit } \\
\hline At least once a month & 7 & 28.0 & 16 & 27.1 & 5 & 22.7 & 28 & 26.4 \\
\hline Less than once a month & 18 & 72.0 & 40 & 67.8 & 17 & 77.3 & 75 & 70.8 \\
\hline \multicolumn{9}{|l|}{ Admission to hospitals } \\
\hline Admitted & 7 & 28.0 & 13 & 22.0 & 3 & 13.6 & 23 & 21.7 \\
\hline Not admitted & 18 & 72.0 & 41 & 69.5 & 17 & 77.3 & 76 & 71.7 \\
\hline \multicolumn{9}{|l|}{ Length of stay (days) $(n=23)$} \\
\hline Median (Q1-Q3) & 3 & $(2-5)$ & 4 & $(2-17.5)$ & 3 & $(3-4)$ & 3 & $(2-6)$ \\
\hline
\end{tabular}


Table 4 Medical expenses in Thailand in the previous 12 months

\begin{tabular}{|c|c|c|c|c|c|c|c|c|}
\hline & Bangkok & $(n=25)$ & Chiang Mai & $(n=59)$ & Other & $(n=22)$ & Total & $(n=106)$ \\
\hline & $n$ & $\%$ & $n$ & $\%$ & $n$ & $\%$ & $n$ & $\%$ \\
\hline \multicolumn{9}{|l|}{ Insurance use } \\
\hline Didn't use & 7 & 28.0 & 13 & 22.0 & 11 & 50.0 & 31 & 29.2 \\
\hline \multicolumn{9}{|l|}{ Used (multiple answer for type) } \\
\hline Travelers' insurance & 14 & 56.0 & 27 & 45.8 & 0 & 0.0 & 41 & 38.7 \\
\hline Japanese public health insurance & 6 & 24.0 & 13 & 22.0 & 3 & 13.6 & 22 & 20.8 \\
\hline Private medical insurance & 0 & 0.0 & 5 & 8.5 & 5 & 22.7 & 10 & 9.4 \\
\hline Thai public medical insurance/benefit & 0 & 0.0 & 0 & 0.0 & 3 & 13.6 & 3 & 2.8 \\
\hline \multicolumn{9}{|l|}{ Total out-of-pocket medical expense (USD) } \\
\hline Median (Q1-Q3) & 62 & $(0-770)$ & 216 & $(46-924)$ & 154 & $(0-616)$ & 154 & $(0-847)$ \\
\hline
\end{tabular}

retirement age or the introduction of a post-retirement employment system in Japan [32].

After more than a decade of Thai long-stay tourism promotion, many Japanese retirees have rooted themselves in Thailand. The majority in the current study (58\%) have been staying in Thailand for more than five years, while only $12 \%$ did so in 2007 [30]. In addition, a majority of the participants (63\%) resided in Thailand for more than 300 days in the previous year. This is understandable since $40 \%$ of our participants have either Thai spouses or do not keep a residence in Japan.

Retirees' use of health services in Thailand is infrequent and primarily for non-serious conditions. Many retirees were observed to have utilized preventive services in Japan more than Thailand with 52\% versus 35\% for health checkups, respectively and $70 \%$ versus $23 \%$ for cancer screenings, respectively. They may feel that such screening services are more accessible in Japan where they are routinely provided by local authorities under the law and user fees are fully or partly subsidized.

Although one-third of the participants had chronic diseases or sequelae, only a quarter of them saw a doctor once a month or more. As expected, treatment for chronic diseases in the cohort was more commonly observed than among working-age Japanese living in Thailand $[8,23]$. However, half of the people who saw a doctor for indicator diseases such as hypertension or diabetes in the previous 12 months did so only in Japan. One possible reason is that patients do not need a doctor's prescription to purchase their medication from private pharmacies in Thailand. Thus, there was no need to visit a doctor unless the disease's condition became worse ${ }^{3}$.

Unlike medical tourists, a majority of retirees intend to go to Japan for treatment of serious diseases. This was particularly high for the Bangkok residents where nearly $80 \%$ indicated this option even though Bangkok holds many

Table 5 Future intention of health service use

\begin{tabular}{|c|c|c|c|c|c|c|c|c|}
\hline & $\begin{array}{c}\text { Bangkok } \\
\text { n }\end{array}$ & $\begin{array}{c}(n=56) \\
\%\end{array}$ & $\begin{array}{c}\text { Chiang Mai } \\
\mathrm{n}\end{array}$ & $\begin{array}{c}(n=144) \\
\%\end{array}$ & $\begin{array}{c}\text { Other } \\
n\end{array}$ & $\begin{array}{c}(n=37) \\
\%\end{array}$ & $\begin{array}{c}\text { Total } \\
\mathrm{n}\end{array}$ & $\begin{array}{c}(n=237) \\
\%\end{array}$ \\
\hline \multicolumn{9}{|c|}{ Preferred place of treatment when one has serious disease } \\
\hline Japan & 44 & 78.6 & 91 & 63.2 & 22 & 59.5 & 157 & 66.2 \\
\hline Thailand & 3 & 5.4 & 39 & 27.1 & 13 & 35.1 & 55 & 23.2 \\
\hline Don't know, other, either & 4 & 7.1 & 11 & 7.6 & 1 & 2.7 & 16 & 6.8 \\
\hline \multicolumn{9}{|c|}{ Preferred place of LTC when one become severely disabled } \\
\hline Japan & 36 & 64.3 & 82 & 56.9 & 11 & 29.7 & 129 & 54.4 \\
\hline Thailand & 7 & 12.5 & 51 & 35.4 & 20 & 54.1 & 78 & 32.9 \\
\hline Don't know, other, either & 8 & 14.3 & 9 & 6.3 & 6 & 16.2 & 23 & 9.7 \\
\hline \multicolumn{9}{|c|}{ Type of LTC in Thailand ${ }^{\mathrm{a}}$ (Multiple answer) } \\
\hline At home & 4 & 57.1 & 27 & 52.9 & 17 & 85.0 & 48 & 61.5 \\
\hline Elderly nursing home & 2 & 28.6 & 11 & 21.6 & 1 & 5.0 & 14 & 17.9 \\
\hline Elderly nursing unit in hospital & 1 & 14.3 & 5 & 9.8 & 3 & 15.0 & 9 & 11.5 \\
\hline Don't know, other & 3 & 42.9 & 11 & 21.6 & 0 & 0.0 & 14 & 17.9 \\
\hline
\end{tabular}

aDenominator in the calculation of percentage is those who answered "Thailand" as preferred place of LTC 
excellent hospitals providing advanced medical technology and Japanese-speaking doctors or translators. Although it requires further study, one of the biggest barriers to seeking treatment in Thailand might be a fear of high medical costs. Compared to the fixed medical fees under Japan's universal health insurance scheme, private medical care costs in Thailand are more expensive [30, 33].

Many of the Japanese retirees living in Thailand have no health insurance. In our study, of those who used health services, one-third paid their medical expenses fully out-ofpocket. It can be reasoned that this does not only stem from individual choice but also from system restrictions. More than half of the participants had withdrawn from the Japanese national health insurance either by choice or by becoming ineligible since they were no longer residents in Japan. Additionally, traveler's insurance is duration specific; generally valid for a maximum of one year from initiation of travel from Japan. At least $20 \%$ of the participants were assumed to be ineligible for traveler's insurance since they did not go back to Japan within one year. More inconveniently, it is commonly inapplicable for chronic diseases [33] and often excludes the elderly. Private medical insurance is not available for many retirees since it imposes an age limit or medical exclusions. Thus, when faced with high medical costs, many retirees typically decide to terminate their long-stay status in Thailand and return to Japan as the individual co-payment is less [28].

The study suggests that Japanese long-stay retirees are relatively healthy since those who need continuing care for chronic or serious diseases do not tend to remain in Thailand. However, unlike working expatriates who are taken care of through occupational health or private insurance schemes, long-stay retirees have to rely on themselves. It is important to promote their access to quality health care services including preventive care in Thailand.

As for LTC, only five cases utilized LTC services in Thailand as either a care recipient or a family carer, suggesting that retiring to Thailand for LTC usage is not yet common. However, many retirees, particularly those living outside of Bangkok, were staying in Thailand in anticipation of using LTC services in the future even though they cannot use Japan's public LTC insurance abroad. The desire for LTC has existed for some time [30] and for many of those living in Thailand over many years, this might not be a vague desire any longer but a realistic option instead. In fact, Japanese retirees established the "Society for the Study of Care and Support in Chiang Mai" in 2014 to develop the LTC environment there [28]. Among those indicating use of LTC in Thailand, around $60 \%$ desired home care; the majority of these responses have a Thai spouse. Since it is expected that most of them will be cared for by their wives or children and/or live-in maids [28], whose round-the-clock LTC service is much cheaper in Thailand than in Japan, demand for trained LTC workers seems to not be very high. However, the answers were based on the current situation in which few quality nursing homes are available at an affordable price [28]. It remains possible that an increase in the supply of appropriate nursing homes will induce demand from current long-stay retirees as well as the growing numbers of so-called "LTC refugees" from Japan, where more than half a million of older adults are on a waiting list for admission to nursing homes under the public LTC insurance system [34, 35].

Though the TAT initially defined long-stay tourists as people who go eventually back to their home country, the real situation is changing in the mature phase of long-stay tourism since the one-year retirement visa is extendable as often as needed so long as one fulfills certain criteria. The percentage of retirees who intends to receive LTC in Thailand is not high but the number is increasing. Whereas previous studies showed that the impact of medical tourists on the Thai health system is marginal $[1,36]$, unlike them, older permanent residents will require medical and nursing care for a long period of time and eventually end-of-life care as well. Once they become frail, they cannot easily return to Japan to seek health services as is currently observed. In addition, many of those who currently have private medical insurance will become ineligible as previously discussed. Authorities in both Thailand and Japan should realize the situation and prepare for the growing need of health services including LTC and end-of-life care.

\section{Limitation}

We recruited participants through Japanese self-help clubs but the majority of long-stay retirees do not actually interact with these clubs since many of them come to Thailand for 1-2 months a year only. As such, our sample is biased towards long-stay retirees mainly living in Thailand. Half of the participants were recruited at club meetings, indicating that they are healthy enough to attend. This selection bias may underestimate medical service usage amongst the long-stay retirees mainly living in Thailand.

In addition, telephone interviews (42 cases) might generate information bias. However, the interviews were done by reading out the questionnaire, in which most of the questions including those about health service use were simple questions on objective facts with dichotomous or multiple options without socially desirable answers. Thus, it was unlikely to cause confusion or hesitation for both questioning and answering. The statistical test between interviewees and self-administered respondents in the same club showed no ostentatious or desirable answers by interviewees. The only matter for concern is that $40 \%$ of the interviewees did not answer whether they had chronic diseases or not, possibly due to the technical error by the interviewer. However, this bias does not militate against our main findings, i.e. infrequent use of health service use in Thailand even among those with chronic diseases. 
There is a possibility of recall bias but it is considered to have little effect on our main findings since they might not forget the experience of serious diseases or continuing care.

\section{Conclusion}

This is the first research on health service usage of Japanese long-stay retirees conducted in various locations in Thailand. The usage of health services amongst Japanese long-stay retirees was found to be currently limited in all study areas due to retirees' preference for Japan over Thailand for health screenings and treatment of chronic or serious diseases. However, the results suggest that the number of older permanent residents who will require health services including LTC and end-of-life care will increase, especially outside of Bangkok. Ensuring access to quality health care is crucial for the promotion of long-stay tourism since it is a decisive factor when individuals choose or terminate long-stay residence.

The potential impact of long-stay tourism promotion on the Thai public health should be acknowledged and investigated by the Thai government, including the tourism authority. Considering that cross-border health seeking behavior depends on the health care system and environment of one's country of origin, further research should focus on retirees from other countries.

\section{Endnotes}

${ }^{1}$ Calculated by $1 \mathrm{USD}=105.79 \mathrm{JPY}$ using mid rate in 2014 at Tokyo Foreign Exchange Market (Ref. Bank of Japan. Reference - Transaction condition at Tokyo Foreign Exchange Market (in 2014). https://www.boj.or.jp/ statistics/market/forex/fxdaily/ex2014.htm/. Accessed 11 May 2016)

${ }^{2}$ Calculated by $1 \mathrm{USD}=32.48 \mathrm{THB}$ using mid rate in 2014 amongst commercial banks in Bangkok Metropolis (Ref. Bank of Thailand. Rates of Exchange of Commercial Banks in Bangkok Metropolis. http://www2.bot.or.th/statistics $/$ ReportPage.aspx?reportID=123\&language=eng.

Accessed 11 May 2016)

${ }^{3}$ Suggested during additional informal group discussion with retirees

\footnotetext{
Acknowledgement

We gratefully acknowledge the technical advice of Dr. Kanitta Bundhamchareon, Dr. Thinakorn Noree, Dr. Cha-aim Patchanee, Dr. Yupawan Thongtanunam, Mrs. Saowapa Jongkitipong, and Ms. Minako Takada. We express our gratitude for the data collection assistance of Ms. Prasinee Mahattanatawee. Sincere appreciation is extended to the representatives of the Japanese clubs who coordinated the data collection and provided valuable comments on the study, as well as all study participants.

$\mathrm{NAJ}$ is a staff member of the WHO. The author alone is responsible for the views expressed in this publication and they do not necessarily represent the decisions
} or policies of the $\mathrm{WHO}$.

\section{Funding}

This study is funded by the International Trade and Health Programme (ITH) under the collaboration between the Royal Thai Government (Health Systems Research Institute, National Health Commission Office, National Health Security
Office, Ministry of Public Health and Thai Health Promotion Foundation) and the World Health Organization (WHO).

\section{Availability of data and materials}

The data will not be shared to protect the privacy of the study participants in accordance with our engagement with the participants as well as the ethical committee.

\section{Authors' contributions}

YM and CA designed the study. CS reviewed the Thai literatures. YM collected and analyzed data and wrote the first draft of the manuscript. YM, CA and NAJ discussed the findings and revised each version of the manuscript. All authors reviewed and approved the final manuscript.

\section{Authors' information}

YM is a researcher at ITH, International Health Policy Program (IHPP), Thailand. CA is a senior researcher at ITH, IHPP.

NAJ is the Director of Asia Pacific Observatory on Health Systems and Policies, WHO Regional Office for South East Asia. Most of his work on the study was done while he worked with WHO Country Office for Thailand. CS is a former research assistant at ITH, IHPP.

\section{Competing interests}

The authors declare that they have no competing interests.

\section{Consent for publication}

Not applicable.

\section{Ethics approval and consent to participate}

The study was approved by the ethical committee of the Institute for the Development of Human Research Protections, Thailand. A letter of approval was obtained from the representative of each Japanese club instead of written consent from individual participants to assure anonymity.

\section{Author details}

${ }^{1}$ International Health Policy Program, Thailand, Ministry of Public Health, Tiwanon Road, Nonthaburi 11000, Thailand. ${ }^{2}$ World Health Organization, Regional Office for South East Asia, World Health House, Indraprastha Estate, Mahatma Gandhi Marg, New Delhi 110002, India. ${ }^{3}$ Previously with International Health Policy Program, Thailand, Ministry of Public Health, Tiwanon Road, Nonthaburi 11000, Thailand.

Received: 11 October 2016 Accepted: 23 February 2017

Published online: 08 March 2017

\section{References}

1. Pachanee CA, Wibulpolprasert S. Incoherent policies on universal coverage of health insurance and promotion of international trade in health services in Thailand. Health Policy Plan. 2006;21(4):310-8.

2. Pocock NS, Phua KH. Medical tourism and policy implications for health systems: a conceptual framework from a comparative study of Thailand, Singapore and Malaysia. Global Health. 2011;7:12.

3. Chanda R. Trade in health services. Bull World Health Organ. 2001;80:158-63.

4. Kanchanachitra C, Lindelow M, Johnston T, Hanvoravongchai P, Lorenzo FM, Huong NL, et al. Human resources for health in southeast Asia: shortages, distributional challenges, and international trade in health services. Lancet. 2011;377(9767):769-81.

5. NaRanong A, NaRanong $\mathrm{V}$. The effects of medical tourism: Thailand's experience. Bull World Health Organ. 2011:89(5):336-44.

6. Arunanondchai J, Fink C. Trade in health services in the ASEAN region. Health Promot Int. 2006;21 Suppl 1:59-66.

7. Department of Health Service Support, Ministry of Public Health. Summary of Thailand Health Tourism. Nonthaburi: 2014.

8. Sakai R, Wongkhomthong SA, Marui E, Laobhripatr S. Patterns of outpatient visit by Japanese male expatriates in Thailand. J Occup Health. 2008;50:103-13.

9. Immigration Bureau. Thai and top 10 nationalities in arrivals to the Kingdom January - December 2557 (2014). http://www.immigration.go.th/nov2004/ base.php?page=stat. Accessed 11 May 2016

10. Embassy of Japan in Thailand. Statistics on the Japanese national residing in Thailand in 2015. http://www.th.emb-japan.go.jp/itpr_ja/consular_zairyuto. html (2017). Accessed 27 Feb 2017. (in Japanese). 
11. Consular Policy Division, Consular Affairs Bureau, Ministry of Foreign Affairs Annual Report of Statistics on Japanese Nationals Overseas - Summary 2015 (As of 1 Oct 2014). Tokyo: 2015. (in Japanese). http://www.mofa.go.jp/mofaj/ files/000086464.pdf. Accessed 27 Feb 2017.

12. Warnes TAM. International Retirement Migration. In: Uhlenberg P, editors. International Handbook of Population Ageing. Dordrecht: Springer; 2009. p. 341-363

13. Toyota $M$, Xiang $B$. The emerging transnational "retirement industry" in Southeast Asia. Int J Sociol Soc Pol. 2012;32(11/12):708-19.

14. Hongsranagon P. Information provision - One more neccessity for long stay tourism of Japanese pensioners in Chiangmai. J Popul Soc Stud. 2006;14(2): 101-10.

15. Policy Bureau, Ministry of Land, Infrastructure, Transport and Tourism. Report on measures of building high-quality sightseeing and resort areas responding to the needs of the older adults. Tokyo: 2006 (in Japanese). http://www.mlit.go.jp/common/000059339.pdf. Accessed 27 Feb 2017.

16. Ono M. Long-stay tourism: Elderly Japanese tourists in the Cameron Highlands, Malaysia. Senri Ethnological Studies. 2010;76:95-110.

17. Long Stay Foundation. The Outline of the "LongStay". http://www.longstay. or.jp/releaselist/english/about.html. Accessed 5 Sep 2016.

18. Long Stay Foundation. Longstay News Vol.1 2016: Top 10 desired countries of Long Stay http://www.longstay.or.jp/archives/056/201604/20160407_001. pdf (2016). Accessed 5 Sep 2016. (in Japanese).

19. Howard RW. Western retirees in Thailand: motives, experiences, wellbeing, assimilation and future needs. Ageing Soc. 2008;28:145-63.

20. Kawahara M. Adaptive strategy of Japanese senior long-term stayers and local community responses in Chiangmai. J Thai Stud. 2010;10:35-55 (in Japanese).

21. Immigration Bureau. Statistics on the alien's stay in the Kingdom 2557 (2014). http://www.immigration.go.th/nov2004/base.php?page=stat. Accessed 16 May 2016

22. Immigration Bureau. Statistics on the alien's stay in the Kingdom during January to December, 2550 (2007). http://www.immigration.go.th/nov2004/ base.php?page=stat. Accessed 16 May 2016

23. Uchikoshi A, Hamada A, lizuka T, Okuzawa H, Unachak V, Thomas J, et al. Disease trend among Japanese expatriates living in Southeast Asia. Jpn J. Occup Med Traumatol. 2003;51:432-6 (in Japanese).

24. Toyota M. Ageing and transnational householding Japanese retirees in Southeast Asia. Int Dev Plan Rev. 2006;28(4):515-31.

25. Legido-Quigley H, Nolte E, Green J, la Parra D, McKee M. The health care experiences of British pensioners migrating to Spain: a qualitative study. Health Policy. 2012;105(1):46-54.

26. Sloane PD, Cohen LW, Haac BE, Zimmerman S. Health care experience of $U$. S. Retirees living in Mexico and Panama: a qualitative study. BMC Health Serv Res. 2013;13:411.

27. Rosenmöller M, Lluch M. Meeting the needs of long-term residents in Spain. In: Rosenmöller M, McKee M, Baeten R, editors. Patient Mobility in the European Union - Learning from experience. Copenhagen: WHO; 2006. p. 59-78.

28. Ueno K. Care strategies among retired Japanese residents in Chiang Mai. J Welf Sociol. 2015;12:57-77 (in Japanese).

29. Chamchan C, Soparat O. Long-stay of the Japanese in Chiangmai: analysis of the determining factors in the pre- and post-period of the visit. Jpn Stud J. 2012;29(1):16-34 (in Thai).

30. Fukahori H, Baba Y, Hioki F, Monkong S, Intarasombat P, Malathum P. Healthcare services for Japanese elderly long-staying in Thailand from the perspective of the patient and healthcare providers: a survey study. Arch Gerontol Geriatr. 2011;53:e168-73.

31. Ikeda S, Shiroiwa T, Igarashi A, Noto S, Fukuda T, Saito S, et al. Developing a Japanese version of the EQ-5D-5L value set. J Natl Inst Public Health. 2015; 64(1):47-55 (in Japanese)

32. Long Stay Foundation. Press Release: Longstay research and statistics 2015 http://www.longstay.or.jp/releaselist/entry-1830.html (2015). Accessed 12 May 2016. (in Japanese).

33. Otsuka Y, Koga T, Abe S, Fukushima S, Tsukui K, Nishikawa T, et al. A survey on the visits to local medical institutions by overseas workers. Jpn J Occup Med Traumatol. 2011:59:69-72.

34. Health and Welfare Bureau for the Elderly, Ministry of Health, Labour and Welfare. Press release - Situation of applicants for special nursing home called Tokuyo. http://www.mhlw.go.jp/file/04-Houdouhappyou-12304250Roukenkyoku-Koureishashienka/0000041929.pdf (2014). Accessed 6 Sep 2016. (in Japanese).
35. A need for special nursing homes. The Japan Times. (21 Apr 2014). http://www.japantimes.co.jp/opinion/2014/04/21/editorials/need-specialnursing-homes/\#.VvoeSdJ97cs. Accessed 29 Mar 2016.

36. Noree T, Hanefeld J, Smith R. Medical tourism in Thailand: a cross-sectional study. Bull World Health Organ. 2016;94(1):30-6.

\section{Submit your next manuscript to BioMed Central and we will help you at every step:}

- We accept pre-submission inquiries

- Our selector tool helps you to find the most relevant journal

- We provide round the clock customer support

- Convenient online submission

- Thorough peer review

- Inclusion in PubMed and all major indexing services

- Maximum visibility for your research

Submit your manuscript at www.biomedcentral.com/submit
Biomed Central 